OPEN ACCESS

ISSN 2541-2841 (online) ISSN 2302-6790 (print)

Edited by: Didik Hariyanto

${ }^{*}$ Correspondence:

Ferry Adhi Dhara ferryadhidharma@umsi da.ac.id

Citation:

Dharma, Ferry A. (2021) Hamabatan Komunikasi Antar Budaya dalam Konflik SunniSyiah di Madura, Kanal, 9(3).

Doi:10.21070/kanal.v9i3.1577

\section{Barriers of Intercultural Communication in the Sunni-Shi'a Conflict in Madura}

\section{Hambatan Komunikasi Antar Budaya dalam Konflik Sunni-Syiah di Madura}

Ferry Adhi Dharma*

Program Studi Ilmu Komunikasi, Fakultas Bisnis, Hukum, dan Ilmu Sosial, Universitas Muhammadiyah Sidoarjo Jl. Mojopahit No. 666B, Sidowayah, Celep, Sidoarjo, Jawa Timur

\begin{abstract}
Until now, the Sunni-Shia conflict in Sampang, Madura has not been fully resolved. Therefore, with a communication science approach, this study will analyze the problems and barriers to intercultural communication that occurs between Sunni and Shia groups, causing eternal conflict. This research was conducted in two places, namely in Karanggayam Village, Omben District, Blu'uran Village, Karang Penang District, Madura, and in Rusunawa Puspa Agro, Sidoarjo. The research method used is the phenomenology of Edmun Husserl. The selection of the phenomenological method was based on the need for research data, namely exploring the experience of intercultural communication of each informant involved in the conflict. The results of the study stated that the barriers to intercultural communication that occur are due to the struggle for social status between Sunni and Shia religious leaders, the low culture of the Madurese community in communicating in the form of firmness in communication, the view of the life of the surrounding community based on syncretism, differences in standards of good or bad values between groups, and perceptions negative relations between groups in the form of prejudice, stereotypes, and ethnocentrism that lead to insincerity in communication. Barriers to Intercultural Communication in the Sunni-Shia conflict in Madura.

Keywords: Barriers of Communication; Communication Between Culture; Sunni-Shi'a Conflict
\end{abstract}

\section{Abstrak}

Sampai saat ini konflik Sunni-Syiah yang terjadi di Sampang, Madura belum sepenuhnya terselesaikan. Karenanya, dengan pendekatan ilmu komunikasi penelitian ini akan menganalisis permasalahan dan hambatan komunikasi antar budaya yang terjadi di antara kelompok Sunni dan Syiah sehingga memunculkan konflik abadi. Penelitian ini dilakukan dua tempat, yakni di desa Karanggayam, kecamatan Omben, desa Blu'uran, kecamatan Karang Penang, Madura, dan di rumah susun Puspa Agro, Sidoarjo. Metode penelitian yang digunakan ialah fenomenologi dari Edmun Husserl. Pemilihan metode fenomenologi didasarkan pada kebutuhan data penelitian yaitu mendalami pengalaman komunikasi anatar budaya tiap informan yang terlibat konflik. Hasil penelitian menunjukkan adanya hambatan komunikasi antar budaya yang terjadi, yakni adanya pertarungan status social antar 
pemuka agama Sunni dan Syiah, budaya rendah masyarakat Madura dalam berkomunikasi yang berbentuk ketegasan komunikasi, pandangan hidup masyarakat sekitar yang didasarkan pada sinkretisme, perbedaan-perbedaan standar baik-buruk atau nilai antar kelompok, dan persepsi negatif antar kelompok yang berbentuk prasangka, stereotip, dan etnosentrisme sehingga memunculkan ketidaktulusan dalam berkomunikasi.

Kata Kunci: Hambatan Komunikasi; Komunikasi Antar Budaya; Koflik Sunni-Syiah.

\section{PENDAHULUAN}

Syiah di Madura sejatinya sudah ada sejak tahun 1980. Kendati demikian, mereka baru eksis beribadah secara terang-terangan atau terbuka pada tahun 2004. Sebelumnya tidak pernah ada masalah dengan warga Sunni, sampai pada akhirnya terjadi konflik dan penyerangan pada pesantren Syiah di tahun 2006, 2011, dan 2012. Pada tahun 2009, diadakan pertemuan antara Majelis Ulama Indonesia (MUI) Sampang bersama dengan Kapolsek dan Danramil Omben membuat pernyataan bersama bahwa Syiah bukan aliran yang sesat karena tidak ditemukan penyimpangan secara agama. Efek dari pernyataan tersebut membuat warga Syiah di Sampang terlindungi secara hukum. Kendati demikian, warga Sunni setempat justru semakin keras menentang keberadaan kelompok Syiah hingga menimbulkan konflik berdarah (Muqoyyidin, 2012: 332). Akibat dari adanya konflik tersebut, 1 orang dari kelompok Syiah meniggal dunia, dan beberapa orang lainnya terluka (Muqoyyidin, 2012: 331).

Demi meredam terjadinya konflik yang lebih besar, pemerintah Kabupaten Sampang merelokasi kelompok Syiah dari Madura menuju Rumah Susun Warga Sidoarjo yang terletak di komplek pasar Puspa Agro Sidoarjo. Relokasi tersebut membawa dampak yang sangat besar bagi kehidupan kelompok Syiah, terutama mengenai kejelasan nasib mereka untuk dapat kembali ke tempat asal mereka sebagaimana mereka hidup damai sebelumnya Bersama masyarakat Karanggayam, Kematan Omben, Sampang.

Menurut Dharma (2016) faktor determinan yang mendasari terjadinya konflik antara kelompok Sunni dengan Syiah di Sampang adalah perbedaan budaya dan komunikasi ritual dalam ajaran yang diyakini oleh masing-masing kelompok. Syiah merupakan kelompok baru yang datang menyampaikan pesan-pesan pembaharuan di tengah masyarakat yang mayoritas Sunni, yang dianggap oleh kelompok Syiah penuh dengan sinkretisme saat melaksanakan ritual keagamaan.

Salah satu contoh dari perbedaan budaya dan komunikasi ritual tersebut dapat dilihat dalam perayaan mauled Nabi Muhammad SAW. Kelompok Syiah menganggap bahwa perayaan mauled Nabi di tiap rumah merupakan tindakan pemborosan, karena masih banyak masyarakat sekitar yang hidup serba kekurangan. Oleh karena itu, kelompok Syiah mengajak masyarakat sekitar untuk merayakan mauled Nabi di Masjid agar biaya perayaan bisa ditanggung secara bersa- ma-sama. Ajakan tersebut ditolak oleh kelompok Sunni, terutama pemuka agama setempat karena dianggap telah merubah nilai-nilai yang sudah ada. Bahkan perbedaan tersebut membuat kelompok Syiah dilabeli sebagai kelompok yang sesat oleh kelompok Sunni.

Hubungan komunikasi yang sudah terjalin akhirnya terputus. Kerusakan hubungan komunikasi tidak hanya terjadi pada level kelompok, namun sudah pada level individu. Karena individu-individu tidak dapat berinteraksi dengan jujur, maka yang terjadi adalah saling berprasangka di antara kedua kelompok.

Samovar, Porter, \& McDaniel (2009) menyebutkan perasangka sebagai sikap yang akan muncul pada perbedaan identitas kultural disamping stereotip, rasisme, dan etnosentrisme. Hal yang ditakutkan ialah kemunculan prasangka negatif akibat kebencian yang sangat.

Pelabelan sesat yang diberikan pada kelompok Syiah oleh kelompok Sunni menjadi salah satu bukti adanya kerusakan hubungan komunikasi antara kelompok Sunni dan Syiah. Oleh karena itu, penting bagi penelitian ini untuk mengetahui dan menganalisa hambatan-hambatan komunikasi antar budaya yang terjadi di antara kedua kelompok tersebut.

Fenomena konflik Sunni-Syiah di Madura menarik minat beberapa akademisi untuk melakukan penelitian. Idan dan Dyson (2015) dalam penelitiannya menyebutkan bahwa konflik Sunni-Syiah terjadi akibat adanya konflik keluarga yang berubah menjadi komunitas. Konflik tersebut semakin meluas salah satunya karena fanatisme masyarakat terhadap komunitas masing-masing.

Sementara itu, Masdar Hilmy (2015) dalam penelitiannya menyebutkan bahwa penyebab terjadinya konflik Suni-Syiah di Madura lebih pada factor politik dan ekonomi. Kehadiran kelompok Syiah dianggap dapat mengancam dominasi dari kelomook Sunni yang telah mengakar di daerah tersebut.

Penelitian ini telah mengambil kajian yang berbeda dari penelitian-penelitian sebelumnya. Dengan menganalisa hambatan-hambatan komunikasi antar budaya dalam konflik Sunni dan Syiah di Madura, penelitian ini diharapkan dapat memperbaiki kembali hubungan komunikasi yang telah rusak di antara keduanya. Selain itu, mengingat tingginya keberagaman di Indonesia, penelitian ini juga diharapkan dapat mencegah terjadinya konflik-konflik serupa yang terjadi di Indonesia dan dunia. 


\section{METODE PENELITIAN}

Penelitian ini dilakukan di tiga tempat yang berbeda, yakni di Desa Karang Gayam, Omben, Sampang, Desa Bluuran, Kecamatan Karang Penang, Sampang, dan komplek rumah susun pasar puspa agro Sidoarjo. Infomran yang berada di Sampang adalah dari kelompok Sunni dan masyarakat yang menyaksikan dan mengalami adanya konflik tersebut, sedangkan kelompok Syiah berada di Sidoarjo.

Metode dan pendekatan penelitian yang digunakan adalah fenomenologi Edmun Husserl. Pemilihan tersebut didasarkan pada kebutuhan data pengalaman komunikasi antar budaya pada tiap informan penelitian. Edmun Hussrel (1983: 5) menyebutnya sebagai kognisi alami. Dimana hubungan manusia dan pengalaman itu sendiri bersifat kontingen. Dengan menggunakan purposive sampling, didapat informan berjumlah 11 orang. Semua informan adalah yang mengalami konflik, baik melihat langsung, merasakan, dan yang menempatkan diri mereka sebagai korban dan pelaku.

\section{HASIL DAN PEMBAHASAN}

Hambatan-hambatan komunikasi muncul sebagai dampak perbedaan budaya dan bentuk simbolik ritual keagamaan antara kelompok Sunni dan Syiah. Perbedaan budaya dan bentuk ritual di antara kelompok tersebut menghasilkan sebuah hubungan komunikasi yang buruk, yang ditandai dengan munculnya stereotip, prasangka buruk, dan etnosentrisme pada pengikut kedua kelompok.

Saling berpersepsi antar kelompok atau golongan adalah suatu keniscayaan. Islam sendiri telah terbagi dalam banyak golongan. Namun seecara garis besar, pecahnya islam dipicu oleh persaingan politik antara Muawwiyah dengan khalifat Ali bin Abi Thalib yang berakhir dengan perang siffin (37H/657M), hanya 25 tahun setelah nabi Muhammad Sallallahu Alaihi Wasallam wafat. Perang tersebut akhirnya melahirkan perjanjian daumat al-jandal yang membagi umat islam meenjadi tiga firqah dan tiga ekspresi yaitu: Sunni, Syiah, dan Khawarij dengan sistem teologinya masingmasing (Maarif, 2015: 192).

Sedikit histori Sunni dan Syiah di atas bukan menjadi hal yang primer bagi masyarakat Madura. Konflik yang terjadi di Madura adalah sebuah bentuk kegagalan komunikasi, karena mereka terbukti telah hidup berdampingan selama kurang lebih 30 tahun. Konflik antara Sunni dan Syiah di Madura lengsung menuju eskalasi karena ada 3 hal yang akan menimbulkan kemarahan besar bagi orang Madura, yakni: agama, isteri, dan tanah. Kegagalan komunikasi yang dimaksud adalah ketidakpahaman kelompok Syiah terhadap 3 hal tersebut sehingga tidak pernah berpikir jika stigma sesat yang dilekatkan pada ajaran agama akan berubah menjadi konflik berdarah.

Sekali lagi bahwa dimensi agama atau keyakinan ini bagi masyarakat Madura sangat penting. Pertarungan antar tokohtokoh agama lokal dapat berubah secara cepat menjadi perta- rungan sosial-budaya, yang melibatkan mayarakat luas karena didasarkan pada nilai "sesat" tadi.

Pada akhirnya kelompok Syiah, yang dalam hal ini minoritas, meskipun sama-sama masyarakat Madura harus meninggalkan pulau Madura karena seakan-akan semua muslim Madura menolak keberadaan mereka. Masyarakat Madura dikenal sebagai masyarakat yang tegas dalam berkomunikasi. Jika terjadi penolakan, maka itu adalah benar, dan hendaknya diikuti agar tidak memunculkan komunikasi verbal dan non-verbal yang lebih keras.

Liliweri (2014: 112) menyebutkan bahwa sistem-sistem kepercayaan telah memainkan peranan penting dalam membentuk undang-undang ataupun peraturan-peraturan di banyak negara. Jika masyarakat di lingkungannya menerapkan peraturan-peraturan berlandaskan sistem kepercayaan yang mereka anut dan dibumbui proses sosial disosiatif, maka dominasi dan hagemoni sistem kepercayaan dominan akan menindas sistem kepercayaan yang represif.

Proses disosiatif yang telah terjadi antara masyarakat sekitar dengan kelompok Syiah mengahasilkan konflik berdarah dan terusirnya kelompok Syiah dari tempat asalnya. Fanatisme agama yang dianut oleh masyarakat sekitar sangat berpengaruh terhadap aktifitas komunikasi sosial-budaya yang penuh intrik dan tidak memberikan penghargaan pada kelompok yang represif.

Hubungan komunikasi yang negative di antara kedua kelompok telah merujuk pada pola komunikasi yang khas. Pola komunikasi dan interaksi tersebut membentuk pola adaptasi yang melibatkan pola pengetahuan, pola perasaan dan pola tindakan dari masyarakat (Littlejohn and Foss, 2011). Proses adaptasi komunikasi pada kedua kelompok menurut Dharma (2016) dibentuk oleh sejarah sosial masyarakat Madura, hierarki social, dan sinkretisme.

\section{Hambatan Komunikasi di Level Individu}

Salah satu factor yang mempengaruhi terjadinya konflik adalah ketegasan masyarakat Madura dalam berkomunkasi. Hal ini dipengaruhi oleh sejarah panjang kehidupan social masyarakat di era colonial. Saat masyarakat Madura dikendalikan oleh Vereenigde Oostindische Compagnie (VOC), pulau Madura dibagi oleh VOC menjadi tiga bagian kabupaten, yang batas-batasnya sampai abad ke19 tetap atau tidak berubah, yakni: Madura (Madura Barat), Pamekasan dan Sumenep.

Dalam prakteknya, Madura Barat selalu dikekang oleh VOC daripada wilayah lainnya. Menurut Jonge (1989) hubungan VOC dengan Madur Barat adalah hubungan raja dan rakyat jelata yang mendapat pinjaman tanah, sementara khusus untuk wilayah Madura bagian timur (Sumenep dan Pamekasan) layaknya mitra.

Pengekangan yang dilakukan oleh VOC pada masyarakat Madura Barat menimbulkan perbedaan cara berkomunikasi masyarakat, mulai dari dialek verbal dan non verbal. Komuni- 
kasi masyarakat Madura Barat, yang dalam hal ini melingkupi wilayah Sampang dan Bangkalan lebih spontan dan terkesan kasar. Dalam pembagian bahasa, masyarakat Sampang dikenal tidak berbahasa halus seperti masyarakat Pamekasan dan Sumenep.

Spontanitas komunikasi masyarakat Sampang menjadi hal yang logis. Ketika anggota masyarakat tidak sepaham dengan kelompok Syiah, maka akan disampaikan secara langsung. Bahkan, salah satu pemuka agama setempat yang bernama Ali Karrar, yang masih memiliki hubungan kekerabatan dengan Tajul Muluk (pimpinan Syiah Sampang) juga mengekspresikan tindak komunikasi yang tegas saat menolak kehadiran kelompok Syiah. Bahkan Ali Kharar sendiri yang menjadi aktor pengusiran kelompok Syiah dari Madura. Hal ini dapat dilihat dalam kutipan wawancara berikut:

"Katanya yang benci Ust. Ali Karrar itu? Ya, datang ke gor sampang, gini, pindahkan, carikan tempat sana, ya pemimpinnya itu." (Informan 8, di Pasar Puspa Agro, Sidoarjo).

Perintah pemindahan kelompok Syiah oleh Ali Karrar langsung direspon oleh Pemkab. Sampang dengan memindahkan kelompok Syiah dari GOR Sampnag ke komplek Rusunawa pasar Puspa Agro Sidoarjo.

Perbedaan dan keragaman cara masyarakat Indonesia dalam berkomunikasi terlihat karena sampai saat ini kelompok Syiah yang berada di Rusunawa Puspa Agro tetap hidup perdampingan dengan masyarakat Sidoarjo dan penghuni Rusunawa lainnya, yang didominasi oleh imigran dari Timur Tengah. Kendati demikian ini bukan sebuah jaminan, karena masyarakat Sidoarjo lebih menggunakan budaya tinggi dalam berkomunikasi, yaitu tidak terangterangan dan mencari aman.

Selain ketegasan komuniksi masyarakat Madura, komunikasi yang dilakukan oleh kelompok Syiah juga dinilai ekslusif oleh masyarakat sekitar. Tindak komunikasi yang ekslusif dari kelompok Syiah telah menimbulkan kebencian sehingga memutuskan banyak silaturahmi dengan masyarakat sekitar.

Keterputusan komunikasi antara kelompok Syiah dengan masyarakat dimanfaatkan oleh pemuka agama dari kelompok Sunni untuk menguatkan realitas kesesatan kelompok Syiah. Selain itu, kondisi juga diperparah dengan adanya perintah dari kyai setempat untuk masyarakat sekitar agar tidak melewati rumah anggota kelompok Syiah dan menerima segala pemberian, termasuk makanan dari kelompok Syiah. Dengan demikian penganut Syiah di Sampang semakin terkucilkan dari aktifitas sosial dan hubungan komunikasi antar masyarakat.

Menurut Barry (1998: 4) isolasi sosial sendiri dapat meliputi eksklusi sosial yang lebih dari sekedar pengucilan. Isolasi sosial (baik dari bentuknya) hendaknya dipahami sebagai variabel: seorang individu atau kelompok tidak hanya secara sosial terisolasi atau tidak tetapi kurang lebih t- erisolasi secara sosial. Tugas dari ilmuwan adalah untuk mengukur seberapa besar isolasi sosial tersebut terjadi dan membedakan antara bentuk isolasi sosial dan isolasi antar pribadi.

Pesan yang disampaikan oleh kyai pada masyarakat sekitar untuk tidak melewati rumah dan menerima pemberian makanan dari anggota kelompok Syiah dapat disebut sebagai isolasi antar pribadi dan sosial. Anggota kelompok Syiah benar-benar dihindari, baik secara individu maupun kelompok.

\section{Hambatan Komunikasi Antar Kelompok}

Ada dua hambatan komunikasi antar kelompok yang terjadi. Pertama, hambatan kelas sosial terjadi antara kelompok Sunni dengan kelompok Syiah, dimana kelompok Syiah menganggap diri mereka lebih mapan dalam berpikir, sehingga menilai ajaran Sunni di sana sebagai ajaran yang kolot dan mulai merebut lahan-lahan strategis dalam kehidupan sosial. Kedua, kelas sosial di Madura lebih dilihat dari lapisan sosial agama yang telah diakui secara turuntemurun yaitu menempatkan pemuka agama sebagai pemilik kelas atas. Kehadiran Tajul Muluk sebagai pemuka agama Syiah dianggap sebagai tandingan baru oleh pemuka agama setempat (Sunni).

Pada akhirnya Tajul dan pengikutnya secara sosial diisolasi dan hanya diijinkan beraktifitas di tengah bukit yang jauh dari pemukiman warga. Akibat dari adanya esklusi social tersebut adalah kerenggangan bahkan keterputusan komunikasi di antara kedua kelompok. Sementara itu, tokohtokoh Sunni semakin gencar memproduksi opini tentang kesesatan Syiah melalui berbagai media dakwah. Tajul Muluk dan pengikutnya semakin tersudut dan pertarungan sosial tersebut dimenangkan oleh tokoh-tokoh Sunni.

Intrik-intrik sosial dan komunikasi, termasuk juga konstruksi makna sesat yang dilekatkan pada kelompok Syiah dan makna kolot yang dilekatkan pada kelompok Sunni menandai masih adanya kontestasi perebutan status hirarkis tokoh kyai di Madura dewasa ini.

Berger dan Luckmann (1966: 72) menyebutkan bahwa aktor-aktor dapat memainkan perannya dalam institusi sosial yang dibangun. Hal tersebut nantinya akan menjadi kebiasaan bersama lingkungan sosial yang dipimpin, baik yang dipaksakan ataupun tidak.

Selain adanya pertarungan kelas sosial, kelompok Syiah juga memproduksi kesalahan kelompok Sunni dengan menganggap bahwa ajaran yang disampaikan oleh kelompok Sunni adalah ajaran yang tidak benar. Salah satunya adalah pendapat Syiah mengenai wajib belajar di sekolah formal yang menimbulkan pertentangan di antara keduanya. Syiah secara frontal juga ingin mengubah kebiasaan warga sekitar seperti menikah di usia dini dan mewajibkan kelompoknya untuk wajib belajar setinggi-tingginya. Padahal, sinkretisme budaya dan agama telah menyatu dengan kebiasaan masyarakat sekitar, sehingga masyarakat lebih terbiasa dengan sekolah informal di pondok pesantren dan melakukan pernikahan dini 
dengan dalih menghidari perzinahan.

Ini dijadikan perbedaan oleh kelompok Sunni karena kyai Sunni menyatakan bahwa ajaran yang dianut Syiah bukan ajaran Islam. Syiah Sampang direpresentasikan sebagai ajaran Tajul Muluk dan ajaran sesat. Hukum tradisional yang diberlakukan di daerah tersebut diidentikkan dengan hukum Islam kultural, oleh karena itu warga sekitar mulai enggan berkomunikasi dengan kelompok Syiah.

Setelah ditelusuri, konflik yang terjadi bukan termasuk dalam jenis konflik antar agama, melainkan konflik perbedaan pendapat dalam satu agama (Islam) yang selanjutnya memunculkan ketegangan dialektis diantara kedua kelompok. Konflik yang terjadi di Sampang, Madura adalah dominasi yang berujung pada resistensi antar kelompok dalam satu Agama. Dominasi agama-budaya Sunni yang sudah melekat pada masyarakat sekitar dijadikan senjata untuk mengutuk keberadaan kelompok Syiah di daerah tersebut. Dengan mengkonstruksi realitas dan membuat mitos kesesatan Syiah, kyai setempat berhasil mengajak kelompok Sunni untuk menyerang kelompok Syiah.

Tajul Muluk dan pengikutnya selalu menganggap bahwa ajaran yang disampaikan adalah geraka pemurnian agama dari kepentingan politik dan ekonomi yang dimainkan oleh pemuka agama setempat. Dari sana lah muncul ketegangan dialogis, yang berujung pada konflik berdarah yang tidak seimbang.

Nilai-nilai yang dipercaya oleh masyarakat sekitar jelas berbeda dengan nilai-nilai yang diyakini oleh kelompok Syiah. Nilai yang diyakini oleh kelompok Sunni lebih mengarah pada sinkretisme dan juga mengarah pada mozaikisme. Di mana ada penyatuan nilai-nilai budaya dengan nilai-nilai Islam pada beberapa ritual keagamaan yang dilakukan sehingga kadang susah untuk dibedakan mana yang lebih dominan antara agama atau budaya. Sedangkan kelompok Syiah hanya mengakui nilai-nilai kebenaran yang berdasar pada ajaran agama yang dipahami, tanpa dikaitkan dengan nilai-nilai budaya. Misalnya kelompok Sunni yang masih tetap menjaga tradisi dengan mengadakan acara peringatan hari besar Islam dari rumah ke rumah, sedangkan Syiah ingin merubah ritual tersebut karena dinilai merugikan masyarakat sekitar secara ekonomi dan hanya menguntungkan pemuka agama setempat karena akan mendapatkan bayaran setelah mengisi acara pengajian dari rumah ke rumah tersebut.

Usaha untuk mengubah ritual keagamaan yang dilakukan oleh kelompok Syiah di atas adalah sia-sia, dan justru menjadi boomerang yang mematikan. Bagi kelompok Sunni, keyakinan atau agama adalah yang telah dianut secara turuntemurun adalah salah satu hal yang akan mereka bela sampai mati.

\section{Hambatan Komunikasi Sosial-Budaya}

Konflik antara kelompok Sunni dengan Syiah yang dimulai dari sifat ekslusif kelompok Syiah dan ekslusi social yang di- lakukan oleh kelompok Sunni pada kelompok Syiah telah berujung pada keterputusan komunikasi di antara keduanya.

Kondisi hubungan komunikasi yang buruk tidak segera ditangani oleh kedua kelompok dan lenih memilih untuk saling mencari pembenaran. Masing-masing kelompok membangun persepsi negative yang memunculkan prasangka buruk, stereotip, dan etnosentrisme dari semua nggota kelompok.

Ada stereotip yang saling dilekatkan oleh kelompok Sunni pada kelompok Syiah, begitu juga sebaliknya. Secara umum kelompok Syiah distereotipkan sebagai ajaran sesat yang suka melakukan ritual keagamaan di luar ajaran Islam dan cenderung aneh, misalnya tuduhan bahwa kelompok Syiah sholat sambal berjoget. Sedangkan kelompok Sunni distereotipkan oleh kelompok Syiah sebagai kelompok yang bodoh dan dan kolot.

Tidak ada yang mau mengalah dalam berkomunikasi, sehingga kebenaran bukan menjadi tujuan komunikasi, melainkan pembenaran atas masing-masing pesan yang ingin disampaikan, sehingga komunikasi yang ada jauh dari keabsahan dan cenderung selalu negative.

Untuk menganalisa hubungan komunikasi yang negative tersebut, penelitian ini mengutip pernyataan Sayoga (2011) yang menyatakan bentuk hambatan komunikasi yang ada dapat dibadi menjadi dua, yaitu di atas air (above waterline) dan yang di bawah air (below waterline).

Menurut Sayoga (2011), faktor-faktor hambatan komunikasi antar budaya yang berada di bawah air adalah faktor-faktor yang membentuk perilaku atau sikap seseorang, hambatan semacam ini cukup sulit untuk dilihat atau diperhatikan karena tidak terlihat secara langsung. Sedangkan yang bersifat di atas air adalah persoalan sosial politik, distribusi ekonomi yang tidak merata, frustasi sosial akibat kesulitan ekonomi, dan lain sebagainya. Jenis-jenis hambatan semacam ini salah satunya berupa ketidaktulusan dalam menjalin interaksi atau dikenal sebagai komunikasi mindlessness. Tumbuh prasangka buruk dari masing-masing kelompok sehingga komunikasi berjalan tidak baik.

Hal yang perlu diketahui bahwa perilaku komunikasi dari kedua kelompok telah dibentuk sebelumnya oleh masingmasing tokoh agama. Penelitian ini menemukan adanya ketidaktulusan dalam berkomunikasi, baik antar penganut aliran dan antar tokoh agama. Keduanya sama-sama memiliki motif, yakni menjaring anggota sebanyak-banyaknya di daerah tersebut, atau dengan kata lain telah terjadi saling berebut anggota kelompok. Akibatnya tentu komunikasi yang tidak jujur tersebut dan memicu disintegrasi sosial di masyarakat.

Komunikasi yang tidak jujur selalu diiringi dengan etnosentrisme. Etnosentrisme yang ditanamkan pada masyarakat sekitar telah diterima dengan baik dan menimbulkan efek negatif yang berkepanjangan. Menurut Samovar (2009) semakin etnosentris, maka yang akan ditimbulkan adalah kecemasan saat berinteraksi. 
Etnosentrisme dapat memunculkan manipulasi informasi. Ketidakpercayaan dalam komunikasi dijelaskan oleh Burgon, et. al (dalam McCornack, et. al., 1996) dengan tahapan berikut: Pertama, penerima yang strategis menggunakan berbagai dimensi informasi, ketika menafsirkan pesan dan menilai kredibilitas komunikator. Burgon, et. al menyampaikan bukti kuat bahwa individu tidak memproses isyarat pesan dengan waspada dan penuh curiga. Kedua, informasi yang diungkapkan dalam pesan yang menipu secara substansial berbeda dari informasi yang benar, yaknin perbedaan yang akan mengakibatkan penerima berinisiatif mendeteksi ulang pesan yang diterima. Ketiga, ketika penerima pesan mendeteksi adanya manipulasi informasi, mereka akan beranggapan telah diperdaya oleh komunikator.

Kelompok Sunni mempertanyakan kredibilitas dari kelompok Syiah yang berbeda secara keyakinan terhadap ajaran, begitu juga sebaliknya. Kewaspadaan dan analisa kedua kelompok lebih didasarkan padapendidikan agama yang sepenuhnya didapat dari kyai atau pondok pesantren.

Perbedaan-perbedaan yang substansial dalam ajaran yang diterima telah dijadikan sebagai referensi utama untuk menolak informasi yang berbeda dengan pandangan masingmasing kelompok. Kendati demikian, tidak ada proses pengkajian ulang yang dilakukan, karena respon yang diberikan adalah langsung tidak percaya pada informasi yang disampaikan oleh komunikator.

Pendeteksian informasi hanya didasarkan oleh ajaran yang dipercaya atau diyakini saja. Ketika sudah berbeda dengan apa yang dipercaya atau diyakini, maka secara langsung komunikan akan menganggap dirinya telah diperdaya oleh komunikator. Bahkan, apapun informasi yang diberikan, meskipun itu benar, kedua kelompok tetap tidak mempercayainya dengan berbagai alasan.

\section{KESIMPULAN}

Secara garis besar hambatan komunikasi antar budaya antara kelompok Sunni dengan Syiah terjadi karena adanya perebutan kelas sosial, sejarah sosial, konstruksi nilai agama, dan nilai-nilai budaya, yang kesemuanya memunculkan stereotip, prasangka, dan etnosentrisme.

Ada tiga tingkatan konflik yang dihasilkan dari adanya hambatan komunikasi yakni: (1) secara individu kelompok Syiah bersifat ekslusif dalam berkomunikasi sehingga memutuskan hubungan komunikasi anatara kelompok Syiah dengan masyarakat, (2) secara kelompok telah terjadi pengucilan yang dilakukan oleh kelompok Sunni kepada kelompok Syiah dengan dalih ajaran sesat, sehingga menambah kebencian masyarakat pada kelompok Syiah, (3) terjadi hambatan secara sosial-budaya akibat dari keterputusan komunikasi antara kelompok Syiah dengan masyarakat. Berawal dari prasangka buruk masyarakat pada kelompok Syiah sehingga memunculkan stereotip kesesatan Syiah secara umum. Kondisi ini diperparah dengan sikap etnosentrisme dari tiap-tiap kelompok sehingga kelompok S- yiah tidak dapat menjelaskan stereotip yang berkembang di masyarakat atau membela diri ketika dikatakan sesat.

\section{UCAPAN TERIMAKASIH}

Peneliti mengucapkan terimaksih kepada pengelolah rekanrekan civitas akademika Universitas Muhammadiyah Sidoarjo atas dukungan dan kerjasamanya, sehingga naskah ini terbit.

\section{REFERENSI}

Barry, Brian. (1998). Social Exclusion, Social Isolation and the Distribution of Income. London: London School of Economics.

Berger, L. Peter, \& Luckmann, Thomas. (1966). The Social Construction of Reality. England: Penguin Group.

Dharma, Ferry A. (2016). Eklusi dan Hambatan Komunikasi dalam Konflik SunniSyiah di Sampang, Madura. Tesis. Surakarta: UNS.

Hilmy, Masdar. (2015). The Political Economy of Sunni-Shi'ah Conflict in Sampang Madura. Al-Jami'ah: Journal of Islamic Studies, 53(1), 27-51.

Husserl, Edmund. (1983). Ideas Pertaining to A Pure Phenomenological Philosophy. Translated by: F. Kersen. Boston: MARTINUS NIJHOFF PUBLISHERS.

Ida, Rachma, dan Dyson, L. (2015). Konflik Sunni-Syiah dan Dampaknya Terhadap Komunikasi Intra-religius pada Komunitas di Sampang-Madura. Masyarakat, Kebudayaan, dan Politik, 28(1), 33-49.

Jonge, de Huub. (1989). MADURA dalam empat zaman: pedagang, perkembangan ekonomi dan Islam. Jakarta: PT. Gramedia.

Liliweri, Alo. (2014). Pengantar Studi Kebudayaan. Bandung: Nusa Media.

Littlejohn, W. Stephen, dan Karen A Foss. (2011). THEORIES Of HUMAN COMMUNICATION. Tenth Edition. Albuquerque. New Mexico: Wadsworth Publishing Company.

Maarif, Syafii, A. (2015). Islam Dalam Bingkai Keindonesiaan dan Kemanusiaan. Bandung: Mizan.

McCornack, et. al. (1996). Speaking of Informatioan Manipulation: Acritical Rejonder. Communication Monographs, 63, 83-92.

Muqoyyidin, Andik W. (2012). POTRET KONFLIK BERNUANSA AGAMA DI INDONESIA (Signifikansi Model Resolusi Berbasis Teologi Transformatif). Analisis, XII(2), 315-340.

Samovar A Larry, Porter E. Richard, \& McDaniel R. Edwin. (2009). Communication Between Cultures. Boston: Wadsworth.

Sayoga, Budi. (2011). Merajut Kembali Komunikasi Antar Budaya di Indonesia. Jurnal Komunikator, 3, (2), 59-78.

Wiyata, Latief. (2013). Mencari Madura. Jakarta: Bidik Phronesis Publisihing.

Conflict of Interest Statement: The authors declare that the research was conducted in the absence of any commercial or financial relationships that could be construed as a potential conflict of interest.

Copyright (C) 2021 Nuffus and Rohaningsih. This is an open-access article distributed under the terms of the Creative Commons Attribution License (CC BY). The use, distribution or reproduction in other forums is permitted, provided the original author(s) and the copyright owner(s) are credited and that the original publication in this journal is cited, in accordance with accepted academic practice. No use, distribution or reproduction is permitted which does not comply with these terms. 